\title{
O conceito de interações ecológicas em livros didáticos de biologia
}

\section{RESUMO}

\section{Caio Castro Freire} $\frac{\text { cdcfreire@gmail.com }}{0000-0002-7027-7318}$ 0000-0002-7027-7318
Faculdade de Filosofia, Ciências e Letras
de Ribeirão Preto (Universidade de São Paulo), Ribeirão Preto, São Paulo, Brasil.

\section{Rafael Gil de Castro}

rafacastro07@hotmail.com

Universidade de São Paulo, São Paulo,

Brasil.

\section{Marcelo Tadeu Motokane}

\section{mtmotokane@ffclrp.usp.br} Faculdade de Filosofia, Ciências e Letras
de Ribeirão Preto (Universidade de São Paulo), Ribeirão Preto, São Paulo, Brasil.

\begin{abstract}
O artigo analisa como é abordado o conceito de interações ecológicas em livros didáticos de biologia do ensino médio, tendo em vista a importância deste material instrucional no contexto escolar, assim como a relevância deste conceito no currículo de biologia, especialmente para a compreensão de fenômenos ecológicos. Utilizando referenciais da transposição didática, do paradigma indiciário e da ecologia, observou-se que os livros didáticos analisados apresentam uma abordagem que pode limitar a compreensão dos estudantes sobre interações ecológicas. Assim, este trabalho aponta a necessidade de planejar melhor a transposição didática de conceitos ecológicos de modo a diminuir o distanciamento entre a ecologia profissional (acadêmica) e a ecologia escolar.
\end{abstract}

PALAVRAS-CHAVE: Interações ecológicas. Livro didático de biologia. Ensino de biologia. Transposição didática. 


\section{INTRODUÇÃO}

O ensino de biologia tem no livro didático um dos seus suportes mais utilizados pelos professores. Ao mesmo tempo, a interação entre seres vivos é um tema muito frequente nas aulas de biologia e faz parte de um conjunto de conceitos importantes para a compreensão de fenômenos e objetos de estudo da ecologia. No presente trabalho procurou-se examinar como o conceito de interações ecológicas é abordado em livros didáticos de biologia para o ensino médio.

\section{Referencial teórico}

\section{Transposição didática e o ensino de ciências}

Chevallard (2000) afirma que o saber sábio, aquele produzido pela comunidade científica sofre várias modificações até se tornar objeto de ensino. 0 primeiro passo compreende a transformação do saber sábio em saber a ensinar, presente nos programas e livros didáticos, enquanto o segundo passo transforma este último em saber ensinado, aquele efetivamente desenvolvido em sala de aula por meio da comunicação educador-educando. Todo esse processo é chamado pelo autor de Transposição Didática (TD).

Durante o percurso dessas mudanças, o conhecimento escolar tende a se afastar de alguns aspectos do conhecimento produzido pelos cientistas e da lógica envolvida nessa produção, já que precisa se adequar a novas demandas e contextos culturais. Alguns autores apontam que o conhecimento científico é frequentemente tratado em sala de aula por meio de uma lógica epistemológica "epistemologia escolar" nos termos de Astolfi e Develay (1990, p. 48), que dificulta a compreensão sobre a natureza da ciência. Nesse sentido, investigar elementos da transposição didática pode ajudar a discutir as relações entre o fazer científico e o ensinar ciências, e refletir sobre a necessidade de aproximar essas duas instâncias de produção de conhecimento.

Olhando as escolas atuais, é possível notar que o conhecimento científico é tratado como pronto e acabado (CACHAPUZ et al., 2005) e não há espaço para discussões sobre o fazer científico ou sobre o processo de produção do conhecimento científico. Tradicionalmente, o ensino tem priorizado a apresentação dos resultados (produtos) da comunidade científica e a memorização de conceitos finalizados (vocabulários, fórmulas, termos técnicos e conceitos-chave) em detrimento de discussões sobre os condicionantes históricosociais da ciência e as práticas específicas utilizadas para propor, justificar e avaliar asserções de conhecimento dentro desse campo. Entender o modo específico que a ciência utiliza para ler, escutar, falar, redigir e atribuir sentido (MAINGUENEAU, 2000), ou resumindo, um novo modo de pensar e ver a realidade, com suas regras e valores próprios, é o que garantiria uma compreensão mais adequada do conhecimento científico e maior aproximação com a cultura científica (SASSERON; 
A falta de oportunidades para trabalhar a natureza da ciência no contexto escolar tem resultado em importantes falhas na educação científica, por exemplo, reforçando para os alunos uma imagem de ciência positivista e neutra (DRIVER et al., 2000). É comum julgar o conhecimento científico como superior a outros tipos de conhecimento e achar que a ciência é infalível por utilizar um método universal capaz de revelar verdades absolutas. Muitas vezes, o cientista é visto como uma pessoa de inteligência acima da média, sem o menor interesse por problemas sociais, dotado de um conhecimento exclusivo, e destituído de valores, emoções, dúvidas, interesses econômicos e políticos. Predomina a visão de uma ciência completamente alienada e neutra à sociedade (GIL et al., 2001).

Assim, um ensino de ciências ampliado para a compreensão epistemológica do empreendimento científico poderia ajudar o aluno a reconhecer que o conhecimento é construído por pessoas, é conjectural e não simplesmente descoberto no mundo, reconhecer que as ideias científicas mudam com o surgimento de novos dados e embates teóricos (SANDOVAL, 2005), e abandonar a visão de uma ciência inequívoca, inquestionável, incontestável (DRIVER et al., 2000).

Nessa perspectiva, é reforçada a relevância de pesquisas que investiguem processos de transposição didática e ajudem a compreender características da ciência e do seu ensino, fornecendo indícios de como a sociedade tem se relacionado e/ou de como deveria se relacionar com os conhecimentos científicos: quais conteúdos são priorizados no contexto escolar, com quais abordagens, e mantendo quais correspondências com a natureza da ciência? É importante realizar esses estudos com diferentes áreas científicas (biologia, física, química) já que epistemologias podem variar dependendo do campo (MAYR, 1988), resultando também em metodologias de ensino domínio-dependentes (KUHN; CHENEY; WEINSTOCK, 2000).

\section{Os livros didáticos como objetos de análise}

Vários estudos sobre transposição didática têm utilizado os livros didáticos como objetos de análise. Batista e colaboradores (2010), por exemplo, investigando conteúdos de virologia em livros-texto, encontraram erros conceituais e ausência de diálogo com outros temas da biologia e com a realidade do aluno, concluindo que estes aspectos podem interferir na aprendizagem. Outros trabalhos como os de Belotto-Batisteti e colaboradores (2010), observaram que o conceito de transformação bacteriana é abordado como uma verdade definitiva (invariável), não deixando espaço para problematizações científicas. Lopes e Vasconcelos (2012) encontraram problemas semelhantes com os conteúdos de filogenia nos livros, tais como a invariabilidade de alguns conceitos e a ausência de diálogo com conhecimentos fundamentais da genética, biologia molecular e paleontologia. Na ecologia, Marandino (2004) cita estudos feitos por Lima (2002), que examinou o conceito de teia alimentar em livros do ensino fundamental e apontou diversas limitações resultantes da transposição didática.

Os livros didáticos podem ser apontados como principais responsáveis pelo acesso geral da população escolar aos conhecimentos científicos (JEFFERY; ROACH, 1994; FRACALLANZA; MEGID-NETO, 2006). Entretanto, o livro não representa uma simples redução ou simplificação da produção acadêmica, mas o resultado de um 
processo de reorganização, reestruturação e resignificação dessa produção, sendo influenciado por diversos fatores como as intenções do governo, das editoras e dos autores (FORQUIN, 1992). Desse modo, o livro didático compõe um tipo de saber sui generis a ser ensinado - o conhecimento escolar que um determinado grupo social em uma determinada época intenciona ensinar -, podendo ser encarado como uma fonte documental importante de pistas ou indícios de um provável cenário educacional, e portanto, um objeto de estudo interessante para investigações na área da educação/ ensino de ciências (ROMA, 2011)

Indício foi adotado aqui como sendo uma pista, um evento ou sinal peculiar capaz de caracterizar um objeto, conforme proposto por Ginzburg (1989) em seu método analítico denominado paradigma indiciário. Para explicar, o autor faz uma analogia ao método utilizado para avaliar a autenticidade de obras de arte:

[...] é preciso não se basear, como normalmente se faz, em características mais vistosas, portanto mais facilmente imitáveis dos quadros [...]. Pelo contrário, é necessário examinar os pormenores mais negligenciáveis, e menos influenciados pelas características da escola a que o pintor pertencia [...] (GINZBURG, 1989, p. 144).

Trazendo o paradigma indiciário para a análise de livros didáticos, não bastaria identificar elementos textuais (por exemplo, definições, jargões e terminologias técnicas) da ciência facilmente reproduzíveis fora da academia e incorporados nesses livros, pois essa apropriação não significa necessariamente a compreensão da natureza da ciência, havendo a necessidade de investigar outros sinais, pistas ou detalhes do texto que permitam descrever melhor as possíveis nuances entre o conhecimento científico e o conhecimento escolar. Resumindo, "o que talvez passasse despercebido ou fosse tido como dado irrelevante em tratamento de dados que procura as repetições e generalizações, com o paradigma indiciário ganha um novo enfoque, é tratado como indício e configura sintomas" (Souza, 2010, p. 44) para analisar fontes documentais como os livros didáticos.

\section{A natureza da ciência ecologia}

A reflexão insuficiente sobre a epistemologia da ecologia foi apontada como um dos obstáculos ao desenvolvimento dessa disciplina nos programas escolares (CHERIF, 1992). A menor atenção dispensada a questões epistemológicas da ecologia, quando comparada à física, química ou à própria biologia, poderia estar relacionada a três principais razões: i) compreender uma área com uma variedade muito grande de subcampos (objetos de estudo e perspectivas teóricometodológicas), ii) ser uma ciência relativamente jovem, e iii) ter pesquisadores menos engajados nesse tipo de discussão (WILSON, 2009).

No século XIX, a biologia concentrou-se nos aspectos funcionais dos organismos individuais, tornando-se essencialmente sinônimo de fisiologia. Entretanto, é necessário reconhecer que de alguma forma a história natural continuou influenciando fortemente o seu desenvolvimento. Não mais praticada como no século XVII e início do XVIII segundo as tradições indutivistas baconiana e aristotélica, a história natural transformada ajudou a desvincular a biologia dos moldes das ciências físicas. Trabalhos como o de Buffon no final do século XVIII teriam contribuído para essa transformação da história natural, que passa de mera descrição dos fatos para a compreensão histórica da natureza como um processo 
temporal e dinâmico (LYON; SLOAN, 1981). A maior aquisição da biologia do século XIX - a teoria evolutiva de Darwin - é amplamente um produto da história natural.

Do mesmo modo, a ecologia foi descrita inicialmente por grandes expoentes da ecologia vegetal americana como uma parte da fisiologia ou até como sinônimo desta (MCINTOSH, 1986). Já os especialistas em ecologia animal descreveram a ecologia como sendo a "nova história natural" ou a "história natural científica" (ELTON, 1927). Portanto, a ecologia parece ter assumido a disputa que antecede a sua origem: a "guerra" entre naturalistas e experimentalistas (fisiologistas) do século XIX, dificultando o posicionamento dos ecólogos, que até hoje discutem se devem enfatizar estudos experimentais típicos da tradição mecanicista e reducionista da fisiologia ou uma abordagem holística, para a qual laboratório e equações matemáticas perfeitas são insuficientes (CANNON, 1978).

A natureza heterogênea dessa ciência parece tornar o debate mais complexo, já que por trabalhar com múltiplos problemas, investigar diferentes grupos de organismos em diferentes níveis, os ecólogos buscam generalizações em diferentes escalas. Os próprios termos holismo e reducionismo se tornam muito relativos para serem aplicados à ecologia como um todo e passam a depender do nível de organização considerado (MARTINS; COUTINHO, 2010). Assim, por exemplo, a autoecologia poderia ser vista como holística com relação à fisiologia, mas reducionista com relação à ecologia de populações.

As pesquisas iniciais dos ecólogos eram predominantemente baseadas no monitoramento ambiental, incluindo observações descritivas e ou comparativas dos fenômenos na natureza por um longo período. Posteriormente, experimentos laboratoriais e em campo foram introduzidos para tentar delimitar melhor os mecanismos causais responsáveis por certos eventos observados e garantir certas generalizações (MCINTOSH, 1986). Com o acúmulo de dados dos estudos observacionais e experimentais, no século XX emergiram novas abordagens envolvendo modelos estatísticos ainda mais comprometidos em prever e generalizar padrões ecológicos (COUDUN; GÉGOUT, 2006). Com o auxílio da tecnologia, essas metodologias continuaram se diversificando e aperfeiçoando e atualmente existem, por exemplo, ferramentas de sensoriamento remoto que ampliaram o potencial dos registros de campo, assim como computadores e softwares capazes de produzir modelagens estatísticas mais complexas. Segundo Wilson (2009), essas modelagens mostram a preocupação em caracterizar e prever o comportamento dos fenômenos estudados, traduzindo de forma matemática os seus mecanismos subjacentes.

Refletindo sobre as contribuições históricas de alguns autores, Wilson (2009) aponta que a introdução de modelos matemáticos e estatísticos na ecologia contribuiu grandemente para o seu desenvolvimento enquanto disciplina científica, avançando de atividades unicamente de descrição e classificação para esforços na constituição de teorias mais gerais. Um exemplo poderia ser o modelo proposto por Paine (1966) sobre a atuação das interações ecológicas na determinação da diversidade de espécies em um ambiente.

Uma extensão dessa proposta de estudar as interações não apenas em nível de organismo e com abordagens descritivas, mas por meio de algumas generalizações teóricas voltadas para níveis hierárquicos mais elevados como comunidades, foi o trabalho de Janzen (1970). Basicamente, a pergunta de pesquisa de Janzen era: "por que duas florestas em ambientes com características 
abióticas semelhantes exibem diversidades diferentes?", e ele se dedicou a explicar certos padrões que vinha observando em algumas comunidades vegetais. Os padrões de determinadas florestas, comparadas a outras, referiam-se ao maior número de espécies de árvore, acompanhado por menor densidade de cada espécie, e distribuição mais regular das plantas adultas.

O modelo explicativo formulado pelo autor é que maiores taxas de predação de sementes, ao diminuírem o recrutamento de plantas nas proximidades de adultos co-específicos, regulam a densidade populacional e distribuição dessas espécies, deixando na floresta espaços abertos para o estabelecimento de outras competitivamente inferiores, e contribuindo assim para aumentar a diversidade nesses ambientes (JANZEN, 1970). Esse mecanismo também foi proposto por Connell (1971) e por isso ficou conhecido como modelo de Janzen e Connell. Esses trabalhos representam um episódio histórico importante por inverter a lógica, predominante na época, de descrever os efeitos dos recursos abióticos na manutenção de uma comunidade, para descrever a influência da própria comunidade de espécies (e suas interações) na determinação dos recursos e na sua regulação.

O grande número de estudos que se propõem a testar o modelo de Janzen e Connell pode estar relacionado à importância desse modelo quando se discute a grande diversidade de espécies existente em florestas tropicais (BLUNDELL; PEART, 2004). Espécies que produzem sementes grandes podem exibir vantagem competitiva em relação a espécies que produzem sementes pequenas, pelo fato de sementes grandes possuírem maiores reservas nutritivas para o estabelecimento das plântulas (BONFIL, 1998). Predadores, entretanto, podem escolher preferencialmente as sementes maiores justamente por elas serem mais nutritivas, favorecendo as espécies de sementes menores (CONDIT et al., 1992; WORM; DUFFY, 2003; WILLS et al., 2006). Portanto, diminuindo o sucesso reprodutivo e alterando o padrão de distribuição espacial dos indivíduos, a predação tende a favorecer a equitabilidade dentro das comunidades vegetais, a diversidade de espécies e a heterogeneidade da vegetação. Foi a partir de contribuições como a de Paine, Janzen e Connell, que as interações ecológicas passaram a ser vistas como as principais forças ecológicas e evolutivas que atuam sobre os organismos tanto em nível individual, como de população e comunidade (HULME; BENKMAN, 2002).

Assim, o conceito de interações parece refletir bem a variedade de níveis hierárquicos e objetos estudados pelos ecólogos profissionais, sendo um tópico interessante para discutir em que medida esse pluralismo é transposto para a ecologia escolar (ou ecologia a ser ensinada). Defende-se que esse tópico poderia ser explorado nos contextos escolares para estabelecer um diálogo entre diversos conceitos biológicos chave, e para ampliar a compreensão epistemológica da ecologia e da ciência como um todo.

\section{Metodologia}

Foram examinados livros didáticos de biologia para o ensino médio aprovados pelo PNLEM 2007/2009 (Quadro 1). 
Quadro 1. Livros didáticos aprovados pelo PNELM 2007/2009 e adotados para o presente estudo.

\begin{tabular}{|c|c|c|c|}
\hline Nome da coleção analisada & Autores & Editora & Ano \\
\hline $\begin{array}{l}\text { I - Biologia das populações } \\
\text { (vol. 3) }\end{array}$ & $\begin{array}{l}\text { José Mariano Amabis e } \\
\text { Gilberto Rodrigues Martho }\end{array}$ & Moderna & 2004 \\
\hline II - Bio (vol.1) & Sônia Lopes e Sérgio Rosso & Saraiva & 2010 \\
\hline III - Biologia (vol.2) & Oswaldo Frota-Pessoa & Scipione & 2006 \\
\hline $\begin{array}{l}\text { IV - Biologia para o ensino } \\
\text { médio (curso completo) }\end{array}$ & $\begin{array}{l}\text { Augusto Adolfo Marcos } \\
\text { Crozetta e Samuel Lago }\end{array}$ & Lago & 2006 \\
\hline V - Biologia (Volume único) & J. Laurence & Nova Geração & 2005 \\
\hline VI - Biologia (volume único) & $\begin{array}{l}\text { José Arnaldo Favaretto e } \\
\text { Clarinda Mercadante }\end{array}$ & Moderna & 2005 \\
\hline VII - Biologia (volume único) & $\begin{array}{l}\text { Sérgio Linhares e Fernando } \\
\text { Gewandsznajer }\end{array}$ & Ática & 2009 \\
\hline VIII - Biologia (vol. 3) & $\begin{array}{l}\text { César da Silva Júnior e Sezar } \\
\text { Sasson }\end{array}$ & Saraiva & 2006 \\
\hline
\end{tabular}


Como todos os livros selecionados dividem os conteúdos por área do conhecimento biológico (biologia celular, genética, zoologia, evolução, botânica), apenas as unidades ou capítulos de ecologia foram lidos e analisados. Dentro dessas unidades, o primeiro passo da análise foi identificar os conteúdos referentes ao tópico "interações ecológicas" e tanto as informações mais genéricas, como aquelas sobre cada interação específica (por exemplo: competição, predação, herbivoria, parasitismo) foram examinadas.

Dessa leitura, emergiram "indícios" ou "sintomas" da abordagem dos livrostexto para o conceito de interações ecológicas, indícios marcantes especialmente para predação e competição, motivo pelo qual o artigo se concentrará nessas duas interações:

Citação explícita de alguns termos que remetem aos níveis hierárquicos da biologia/ecologia: organismo, população e comunidade.

Uso recorrente de termos que podem reforçar juízo de valor sobre os efeitos ou consequências das interações ecológicas.

Apresentação de cada interação de forma isolada.

Nenhuma relação com a ideia de biodiversidade ou diversidade de espécies.

\section{Resultados e discussão}

Conforme apresentado na introdução, a reflexão sobre questões históricas e epistemológicas da biologia/ecologia, e mais especificamente, sobre alguns modelos científicos propostos por ecólogos, aponta que na ciência profissional, o conceito de interações ecológicas é discutido em vários níveis hierárquicos e são explicadas as consequências dessas interações tanto para um organismo (aquele que preda ou é predado, por exemplo), como para uma população, comunidade, ecossistema ou para a biodiversidade como um todo.

O tratamento de uma interação ecológica em vários níveis hierárquicos ajuda a relativizar juízos de valor sobre sua ocorrência, pois estes julgamentos passam a depender do foco de estudo considerado. No senso comum os predadores são animais ferozes e vorazes, ou até mesmo maus. Essa concepção está presente em desenhos animados, gibis, revistas e outras mídias que tratam o fato de um predador matar sua presa para se alimentar como sendo um fato ruim. Se focarmos os organismos que são predados, a ocorrência da predação pode levar à ideia de prejuízo, para uma comunidade (e a sua diversidade de espécies), porém isso não é necessariamente verdade. Visto sob outra perspectiva, os predadores são importantes para o controle da quantidade de presas, garantindo a sobrevivência das presas e evitando o esgotamento dos recursos que elas necessitam para viver.

Ao trabalhar com níveis superiores como comunidade, os ecólogos passam a considerar a atuação conjunta de algumas interações e a relação desses conceitos com o conceito de diversidade: a diversidade local sendo regulada pela atuação de espécies competidoras, que por sua vez sofrem influência de predadores (PAINE, 1966). Abordar esse tipo de formulação ou generalização teórica amplia a compreensão sobre os fenômenos naturais, afinal as interações ecológicas não ocorrem de forma isolada na natureza. 
Entretanto, olhando os livros didáticos aprovados pelo PNLEM 2007/2009, percebeu-se que o tópico interações ecológicas é majoritariamente tratado apenas em nível de organismo. O primeiro indício é a citação explícita de vocábulos que em sua maioria remetem à ideia de relações indivíduo-indivíduo (coluna B do Quadro 2): "um indivíduo de uma espécie (predador) mata um indivíduo de outra (presa)"; "o consumidor mata e come outro indivíduo"; "um animal (predador) ataca e devora o outro (presa)". Apesar de em alguns casos também aparecerem as palavras população, espécie e comunidade, essas são utilizadas apenas para esclarecer se os organismos envolvidos na predação ou competição pertencem a uma mesma espécie ou afirmar que todos fazem parte de uma mesma comunidade. Portanto, o mecanismo causal privilegiado pelos livros permanece sendo aquele que ocorre em nível de organismo e não há explicação de como as interações ecológicas atuam em comunidades.

A coluna C do Quadro 2 aponta os termos usados para qualificar os efeitos das interações, outro indício importante e que reforça o primeiro. Todos os livros, com exceção da obra de Oswaldo Frota-Pessoa ("Biologia", v. 2, Editora Scipione, 2006), usam os adjetivos "positiva"/"negativa", ou "harmônica"/"desarmônica" para classificar uma interação. Tratar a predação como negativa ou prejudicial é olhar as consequências dessa interação apenas para o organismo que é predado, e desconsiderar o seu papel ecológico em outros níveis hierárquicos fundamentais da biologia. O uso dessas classificações não relativiza o papel ou função das interações ecológicas, mas ao contrário, poderia favorecer a imagem de alguns organismos e processos como sendo os "vilões" ou agentes de desequilíbrio dentro de uma dicotomia entre o que é bom e ruim para um sistema biológico.

Foram observadas menções à importância ou ao efeito positivo das interações apenas em nível de população e o único livro que descreve esse efeito é o Amabis e Martho ("Biologia das populações", v. 3, Editora Moderna, 2004): "(...) Do ponto de vista ecológico, a predação é um mecanismo que regula a densidade populacional, tanto para presas como para predadores" (coluna C); as outras obras se limitam a afirmações vagas do tipo: "são importantes para o equilíbrio das populações" ou "muitas vezes é benéfica para a população de presas", não esclarecendo os motivos que geram esse equilíbrio ou benefício.

Finalmente, o terceiro e quarto indícios de que os livros priorizam a abordagem de níveis hierárquicos inferiores são respectivamente: a ausência de abordagem conjunta dos conceitos de predação e competição e da relação destes com o conceito de diversidade de espécies, o que não cabe em modelos explicativos voltados para a ecologia de comunidades, como o modelo de Janzen e Connell, por exemplo. Em nenhum livro há sequer a menção de interações ecológicas como as principais forças ecológicas e evolutivas responsáveis pela manutenção da diversidade de espécies em comunidades biológicas (Quadro 2).

Outro resultado que merece atenção é a presença de um erro conceitual grave: a ideia de que predação é uma interação que só ocorre entre animais: Livros I, III e IV (coluna B do Quadro 2). 


\begin{tabular}{|c|c|c|}
\hline A. Coleção & $\begin{array}{l}\text { B. Uso de termos que remetem aos níveis } \\
\text { hierárquicos da biologia }\end{array}$ & $\begin{array}{l}\text { C. Uso de termos para qualificar os } \\
\text { efeitos das interações ecológicas }\end{array}$ \\
\hline I & $\begin{array}{l}\text { "Competição intra-específica é a } \\
\text { disputa, entre indivíduos de mesma } \\
\text { espécie, por um ou mais recursos do } \\
\text { ambiente." } \\
\text { "Quando duas espécies de uma } \\
\text { comunidade disputam os mesmos } \\
\text { recursos do ambiente, pode-se dizer que } \\
\text { seus nichos ecológicos se 'sobrepõem', e } \\
\text { ocorre competição interespecífica." } \\
\text { "Predação é a relação em que uma } \\
\text { espécie animal, predadora, mata e come } \\
\text { indivíduos de outra espécie animal, que } \\
\text { constituem suas presas." }\end{array}$ & $\begin{array}{l}\text { "Relações ecológicas } \\
\text { negativas (...)" } \\
\text { "Do ponto de vista } \\
\text { individual, as espécies predadoras } \\
\text { beneficiam-se, enquanto as presas } \\
\text { são prejudicadas. Do ponto de vista } \\
\text { ecológico, a predação é um } \\
\text { mecanismo que regula a densidade } \\
\text { populacional, tanto para presas } \\
\text { como para predadores (...) da maior } \\
\text { importância para a sobrevivência } \\
\text { de ambas." }\end{array}$ \\
\hline II & $\begin{array}{l}\text { "A palavra competição refere-se à } \\
\text { disputa entre indivíduos por recursos do } \\
\text { ambiente que não existem em quantidade } \\
\text { suficiente para todos." } \\
\text { "A interação é do tipo predação } \\
\text { quando o o consumidor mata e come outro } \\
\text { indivíduo, suprimindo-o da população." }\end{array}$ & $\begin{array}{c}\text { "(...) } \\
\text { desarmônicas ou negativas (...)" } \\
\text { "Entretanto (...) também } \\
\text { podem ter efeitos positivos, pois } \\
\text { são importantes para o equilíbrio } \\
\text { das populações que interagem." }\end{array}$ \\
\hline III & $\begin{array}{l}\text { "Uma das maneiras que os animais } \\
\text { usam, para arranjar comida, é caçar } \\
\text { animais de outra espécie. Os predadores } \\
\text { matam a presa para comê-la, ou a engolem } \\
\text { viva, como as cobras." } \\
\text { "Os predadores usam os órgãos de } \\
\text { que dispõem para capturar a presa. As } \\
\text { galinhas bicavam e engoliam (...) mas um } \\
\text { belo percevejo que apareceu tinha uma } \\
\text { técnica diferente: enfiava a tromba nas } \\
\text { lagartas, como uma agulha de injeção, } \\
\text { para sugá-las." }\end{array}$ & $\begin{array}{l}\text { Termos (qualificadores) } \\
\text { ausentes }\end{array}$ \\
\hline IV & \begin{tabular}{l}
\multicolumn{2}{c}{ "Competição intra-específica: } \\
disputa pelos mesmos recursos \\
ambientais, como alimento, espaço ou \\
parceiro sexual."
\end{tabular} & 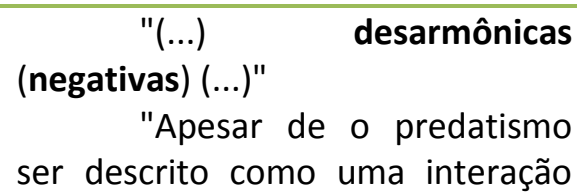 \\
\hline
\end{tabular}




\begin{tabular}{|c|c|c|}
\hline & $\begin{array}{l}\text { "Competição interespecífica: } \\
\text { disputa pelos mesmos recursos devido à } \\
\text { ocupação de nichos ecológicos similares." } \\
\text { "Predatismo: } \underline{\text { um animal }} \\
\text { (predador) ataca e devora o outro (presa)." }\end{array}$ & $\begin{array}{l}\text { (...) negativa para a presa, pode-se } \\
\text { afirmar que os predadores têm um } \\
\text { efeito positivo sobre a população } \\
\text { de presas." }\end{array}$ \\
\hline $\mathbf{V}$ & 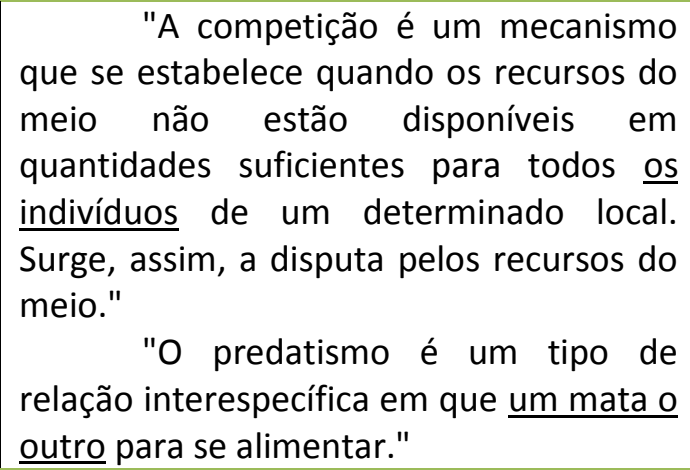 & $\begin{array}{l}\text { "(...) relações desarmônicas } \\
\text { ou interações negativas. Você deve } \\
\text { ter sempre em mente que essa } \\
\text { classificação se aplica ao que ocorre } \\
\text { entre indivíduos, pois o resultado } \\
\text { final para a população é sempre } \\
\text { positivo." }\end{array}$ \\
\hline VI & $\begin{array}{l}\text { "Competição. É a disputa pelos } \\
\text { mesmos recursos ambientais (como água, } \\
\text { alimento, espaço e luz) entre indivíduos da } \\
\text { mesma espécie (competição intra- } \\
\text { específica) ou de espécies diferentes } \\
\text { (competição interespecífica)." } \\
\text { "Predação. É a associação em que } \\
\text { um indivíduo de uma espécie (predador) } \\
\text { mata um indivíduo de outra (presa), que } \\
\text { lhe serve de alimento." }\end{array}$ & $\begin{array}{c}\text { "Relações desarmônicas } \\
\text { (ou negativas) (...)" }\end{array}$ \\
\hline VII & $\begin{array}{l}\text { "A competição intra-específica } \\
\text { (ocorre entre indivíduos da mesma } \\
\text { espécie) (...)" } \\
\text { "Quando duas espécies diferentes } \\
\text { que vivem na mesma área usam o mesmo } \\
\text { tipo de alimento ou disputam algum } \\
\text { recurso, estabelece-se uma competição } \\
\text { que pode eliminar uma das espécies da } \\
\text { comunidade." } \\
\text { "Predatismo. Nesse tipo de } \\
\text { relação, um organismo (predador) mata } \\
\text { outro (presa) para se alimentar." }\end{array}$ & $\begin{array}{c}\text { "(...) } \\
\text { desarmônicas }(\ldots) "\end{array}$ \\
\hline VIII & 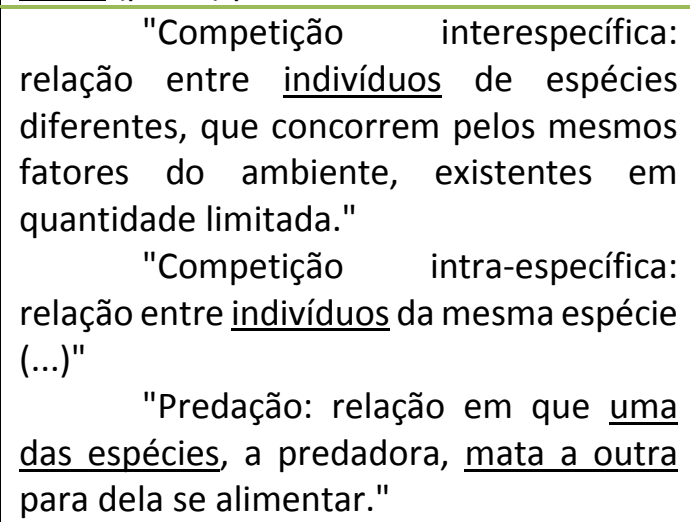 & $\begin{array}{l}\text { "(...) relações } \\
\text { desarmônicas, também chamadas } \\
\text { de interações negativas." } \\
\text { "A predação, embora cause } \\
\text { a morte de alguns indivíduos, } \\
\text { muitas vezes é benéfica para a } \\
\text { população de presas." }\end{array}$ \\
\hline
\end{tabular}


Portanto, somando os indícios, é possível apontar que o conceito de interações ecológicas apresentado pelos livros didáticos se distancia do conhecimento científico: ao priorizar interações em nível de organismo, classificálas como positivas/negativas (harmônicas/prejudiciais), não abordá-las de forma conjunta e não descrever como atuam na ecologia de comunidades (por exemplo, na regulação da diversidade de espécies). Refinando a análise, foram identificados três níveis crescentes de distanciamento:

1) Obras que relativizam as consequências negativas de algumas interações, mas explicando-as em nível de populações - Livro I (ver Quadro 2).

2) Obras que reconhecem seus efeitos para populações, mas sem explicá-los Livros II, IV, V e VIII.

3) Obras que não mencionam vantagens ou a importância das interações Livros III, VI e VII (apesar do livro III não usar os adjetivos "negativa" ou "desarmônica", ele apresentou todos os outros indicativos para enquadramento nessa categoria).

\section{Considerações finais}

Comparando alguns indícios de como os livros didáticos abordam o conceito de interações ecológicas, foi possível caracterizar relações entre a ecologia escolar e a ciência ecologia. Foram observados três níveis ou categorias de distanciamento (falta de correspondência) entre esses saberes, no sentido de quais níveis hierárquicos da biologia são contemplados pelo conceito em questão.

É importante ressaltar que o presente trabalho não se configura como um esforço para desqualificar o livro didático. Ao contrário, conforme apresentado na introdução, esta investigação está orientada pelo referencial da transposição didática e desse modo, reconhece a importância e necessidade do processo de transformação dos conhecimentos científicos em saberes adequados a outros contextos e públicos.

É claro que nem todos os aspectos da ecologia profissional podem ou devem ser contemplados na escola, principalmente porque uma sala de aula tem regras e compromissos epistêmicos diferentes daqueles partilhados entre cientistas, e o ensino de ecologia não tem como objetivo formar ecólogos.

Entretanto, se algumas modificações são necessárias durante a transposição de conceitos da ecologia, interessa perguntar sobre aquelas que deveriam ser evitadas para melhorar a compreensão epistemológica dos alunos sobre o que é essa ciência, o que e como ela produz. Não se trata de introduzir no ensino médio os modelos matemáticos, estatísticos e as teorizações dos ecólogos na forma como são produzidos, mas simplesmente discutir o grau de simplificação de alguns materiais didáticos, e a necessidade de nos limitarmos a essas abordagens. Interessa questionar: "por que limitar a abordagem de conceitos como o de interações ecológicas e perder a chance de discutir esses processos nos níveis e escalas que talvez mais interessem à sociedade?; qual a importância de compreender como um organismo se alimenta ou morre e se isso é positivo ou negativo, e a importância de compreender como uma floresta ou um lago se sustentam e mantém sua biodiversidade?". 
Pensando nisso, diante da escassez nos livros-texto para ensino médio de discussões sobre níveis hierárquicos superiores da ecologia, o Grupo de Pesquisa em Linguagem e Ensino de Ciências (LINCE) tem investido na elaboração de sequências didáticas com temas da "ecologia de comunidades", uma delas inclusive abordando predação de sementes, para exemplificar que essa relação não ocorre somente entre animais. Espera-se que a aplicação dessas atividades permita avançar na discussão sobre como realizar processos de transposição didática que culminem em oportunidades de ensino e aprendizagem de uma ecologia mais próxima dos conhecimentos de referência. 


\title{
The concept of ecological interactions in biology textbooks
}

\begin{abstract}
The article analyzes how the concept of ecological interactions is approached by high school biology textbooks, considering the importance of these instructional materials in school context and the relevance of this concept for biology curriculum. The didactic transposition theory of Chevallard, the Ginzburg's evidentiary paradigm and references from ecology were used as theoretical background for analysis of textbooks. The textbooks showed a conceptual framework that can hinder the students' understanding of ecological interactions. Thus, this work highlights the need to better plan didactic transposition of ecological concepts, in order to bridge the gap between professional ecology and school ecology.
\end{abstract}

KEYWORDS: Ecological interactions. Biology textbooks. Biology teaching. Didactic transposition. 
À CAPES (Coordenação de Aperfeiçoamento de Pessoal de Nível Superior) e ao CNPq (Conselho Nacional de Desenvolvimento Científico e Tecnológico) pelo suporte financeiro, e ao grupo de pesquisa LINCE (Linguagem e Ensino de Ciências).

\section{NOTAS}

\section{REFERÊNCIAS}

ASTOLFI, J.; DEVELAY, M. A Didática das Ciências. Campinas: Papirus, 1990.

BATISTA, M. V. A.; CUNHA, M. M. S.; CÂNDIDO, A. L. Análise do tema virologia em livros didáticos de biologia do Ensino Médio. Ensaio: Pesquisa em Educação em Ciências, v. 12, p. 145-158, 2010.

BELOTTO-BATISTETI, C.; NABUCO DE ARAÚJO, E; CALUZI, J. Os experimentos de Griffith no Ensino de Biologia: a Transposição Didática do conceito de Transformação nos livros didáticos. Ensaio: Pesquisa em Educação em Ciências, v. 12, p. 1-21, 2010.

BLUNDELL, A. G.; PEART, D. R. Density-dependent population dynamics of a dominant rain forest canopy tree. Ecology, v. 85, p. 704-715, 2004.

BONFIL, C. The effects of seed size, cotyledon reserves, and herbivory on seedling survival and growth in Quercus rugosa and Q. laurina (Fagaceae). American Journal of Botany, v. 85, p. 79-87, 1998.

CACHAPUZ, A.; GIL, D.; CARVALHO, A. M. P.; PRAIA, J.; VILCHES, A. A Necessária Renovação do Ensino de Ciências. São Paulo: Cortez, 2005.

CANNON, S. F. Science in Culture: The Early Victorian Period. New York: Dawson and Science History, 1978.

CHERIF, A. H. Barriers to ecology education in North American high schools: another alternative perspective. Journal of Environment Education, v. 23, p. 3646, 1992.

CHEVALLARD, Y. La transposición didáctica: del saber sabio al saber enseñado. 
CONDIT, R.; HUBBELL, S. P.; FOSTER, R. B. Recruitment near conspecific adults and the maintenance of tree and shrub diversity in a neotropical forest. American Naturalist, v. 140, p. 261-286, 1992.

CONNELL, J. H. On the role of natural enemies in preventing competitive exclusion in some marine animal and in rain forest trees. In: Den Boen, P.J.; Gradwell, P.R. (eds.). Dynamics of populations. Wageningen: Pudoc, p. 298-312, 1971.

COUDUN C.; GÉGOUT J. C. The derivation of species response curves with Gaussian logistic regression is sensitive to sampling intensity and curve characteristics. Ecological Modelling, v. 199, p. 164-175, 2006. Disponível em: <http://dx.doi.org/10.1016/j.ecolmodel.2006.05.024>. Acesso em: 12 abr. 2010.

DRIVER, R.; NEWTON, P.; OSBORNE, J. Establishing the norms of scientific argumentation in classrooms. Science Education, v. 84, p. 287-312, 2000.

ELTON, C. Animal Ecology. London: Sidwick \& Jackson, 1927.

FORQUIN, J. C. Saberes escolares, imperativos didáticos e dinâmicas sociais. Teoria \& Evolução, v.5, p. 28-49, 1992.

FRACALLANZA, H.; MEGID-NETO, J. O livro didático de Ciências no Brasil. Campinas: Editora Komedi, 2006.

GIL PÉREZ, D.; MONTORO, I. F.; CARRASCOSA, J.; CACHAPUZ, A.; PRAIA, J. Para uma imagem não deformada do trabalho científico. Ciência \& Educação, v. 7, p. 125-153, 2001.

GINZBURG, C. Mitos, emblemas e sinais: morfologia e história. São Paulo: Companhia das Letras, 1989.

HULME, P. E.; BENKMAN, C. W. Granivory. In: Herrera, C.M.; Pellmyr, O. (eds.). Plant Animal Interactions. An Evolutionary Approach. Oxford: Blackwell Science, p. 77-154, 2002.

JANZEN, D. H. Herbivores and the number of trees species in tropical forests. American Naturalist, v. 104, p. 501- 528, 1970.

JEFFERY, K. R.; ROACH, L. E. A study of evolutionary protoconcepts in pre-high 1994. 
KUHN, D.; CHENEY, R.; WEINSTOCK, M. The development of epistemological understanding. Cognitive Development, v. 15, p. 309-328, 2000.

LIMA, M. J. G. S. Dos saberes científicos aos saberes escolares: uma proposta metodológica para o estudo da transposição didática do conceito de teia alimentar. Dissertação de mestrado. Universidade Federal Fluminense, Rio de Janeiro, 2002.

LOPES, W.R; VASCONCELOS, S.D. Representação E Distorções Conceituais Do Conteúdo “Filogenia” Em Livros Didáticos De Biologia Do Ensino Médio. Ensaio: Pesquisa em Educação em Ciências, v. 14, p. 149-165, 2012.

LYON, J.; SLOAN, P. R. From Natural History to the History of Nature: Readings from Buffon and His Critics. Notre Dame: University of Notre Dame Press, 1981.

MAINGUENEAU, D. Termos-chave da análise do discurso. Belo Horizonte: Editora UFMG, 2000. (Tradução do original francês Les termes clés de l'analyse du discours, 1987).

MARANDINO, M. Transposição ou recontextualização? Sobre a produção de saberes na educação em museus de ciências. Revista Brasileira de Educação, v.26, p. 95-108, 2004.

MARTINS, R. P.; COUTINHO, F. A. Possibilidades e limitações da análise e síntese em Ecologia: uma discussão necessária na formação de ecólogos. Revista Brasileira de Pós-Graduação, v. 7, p. 36-54, 2010.

MAYR, E. Toward a new philosophy of biology. Cambridge: Harvard University Press, 1988.

MCINTOSH, R. P. The background of Ecology: Concept and Theory. Cambridge: Cambridge University Press, 1986.

PAINE, R. T. Food Web Complexity and Species Diversity. The American Naturalist, v. 100, p. 65-75, 1966.

ROMA, V. N. Os livros didáticos de Biologia aprovados pelo Programa Nacional do Livro Didático para o Ensino Médio (PNLEM 2007/2008): a evolução biológica em questão. Dissertação de Mestrado. Universidade de São Paulo, São Paulo, 2011. 
SANDOVAL, W. A. Understanding students' practical epistemologies and their influence on learning through inquiry. Science Education, v. 89, p. 634-656, 2005.

SASSERON, L. H.; CARVALHO, A. M. P. Uma análise de referenciais teóricos sobre a estrutura do argumento para estudos de argumentação no ensino de ciências. Revista Ensaio, v. 13, p. 243-262, 2011.

SOUZA, L. S. Compreensão leitora nas aulas de Ciências. Tese de Doutorado. Universidade de São Paulo, São Paulo, 2010.

WILLS, C.; HARMS, K. E.; CONDIT, R.; KING, D.; THOMPSON, J.; HE, F. L.; MULLERLANDAU, H. C.; ASHTON, P.; LOSOS, E.; COMITA, L.; HUBBELL, S.; LAFRANKIE, J.; BUNYAVEJCHEWIN, S.; DATTARAJA, H. S.; DAVIES, S.; ESUFALI, S.; FOSTER, R.; GUNATILLEKE, N.; GUNATILLEKE, S.; HALL, P.; ITOH, A.; JOHN, R.; KIRATIPRAYOON, S.; DE LAO, S. L.; MASSA, M.; NATH, C.; NOOR, M. M. S.; KASSIM, A. R.; SUKUMAR, R.; SURESH, H. S.; SUN, I. F.; TAN, S.; YAMAKURA, T.; ZIMMERMAN, E. Nonrandom processes maintain diversity in tropical forests. Science, v. 311, p. 527-531, 2006.

WILSON, B. Integrated History and Philosophy of Science 2. Notre Dame: University of Notre Dame Press, 2009.

WORM, B.; DUFFY, J. E. Biodiversity, productivity and stability in real food webs. Trends in Ecology and Evolution, v. 18, p. 628-632, 2003.

Recebido: 10 fev. 2015

Aprovado: 14 jul. 2016.

DOI: http://dx.doi.org/10.3895/rbect.v9n2.2773

Como citar: FREIRE, C. C.; CASTRO, R. G.; MOTOKANE, M. T. O conceito de interações ecológicas em

livros didáticos de biologia. Revista Brasileira de Ensino de Ciência e Tecnologia, v. 9, n. 2, 2016.

Disponível em: <https://periodicos.utfpr.edu.br/rbect/article/view/2773>. Acesso em: 8/11/2016.

Correspondência:

Marcelo Tadeu Motokane

Av Bandeirantes, 3900, 14040-901 - Ribeirão Preto - São Paulo

Direito autoral: Este artigo está licenciado sob os termos da Licença Creative Commons-Atribuição 4.0 Internacional.

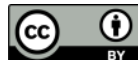

